\title{
Impact of copy number variant and single nucleotide polymorphism of the programmed death-ligand 1 gene, programmed death-ligand 1 protein expression and therapy regimens on overall survival in a large group of Caucasian patients with non-small cell lung carcinoma
}

\author{
ANNA GRENDA $^{1}$, PAWEŁ KRAWCZYK ${ }^{1}$, TOMASZ KUCHARCZYK ${ }^{1}$, JUSTYNA BŁACH $^{1}$, \\ KATARZYNA RESZKA ${ }^{2}$, IZABELA CHMIELEWSKA ${ }^{1}$, JAROSŁAW BUCZKOWSKI ${ }^{1}$, ROBERT KIESZKO ${ }^{1}$, \\ JAN SIWIEC ${ }^{1}$, TOMASZ KUBIATOWSKI ${ }^{3}$, ALEKSANDRA BOŻYK ${ }^{1}$, KINGA KRUKOWSKA ${ }^{2}$, BOŻENA JAROSZ ${ }^{4}$, \\ IWONA PAŚNIK ${ }^{5}$, JULIUSZ PANKOWSKI ${ }^{6}$, DARIA ŚWINIUCH ${ }^{7}, \mathrm{KATARZYNA} \mathrm{STENCEL}^{7}$, MICHAŁ GIL ${ }^{2}$, \\ KINGA LEW $^{1}$, RODRYG RAMLAU ${ }^{7}$, ALEKSANDRA SZCZECSNA ${ }^{8}$, SEBASTIAN FIDLER ${ }^{9}$, ANDRZEJ SIERACKI ${ }^{10}$, \\ ANDRZEJ KAŻARNOWICZ ${ }^{11}$, PIOTR SERWATOWSKI ${ }^{12}$, TOMASZ GRODZKI ${ }^{13}$ and JANUSZ MILANOWSKI ${ }^{1}$ \\ ${ }^{1}$ Chair and Department of Pneumology, Oncology and Allergology, Medical University of Lublin, 20-090 Lublin; \\ ${ }^{2}$ Institute of Genetics and Immunology Genim LCC, 20-609 Lublin; ${ }^{3}$ Department of Clinical Oncology, \\ Saint Jan of Dukla Oncology Centre of the Lublin Region; ${ }^{4}$ Chair and Department of Neurosurgery and \\ Paediatric Neurosurgery and ${ }^{5}$ Chair and Department of Clinical Pathomorphology, Medical University of Lublin, \\ 20-090 Lublin; ${ }^{6}$ Department of Pathology, Specialist Hospital for Lung Diseases 'Rebirth' Klara Jelska, 34-500 Zakopane; \\ ${ }^{7}$ Chair and Department of Clinical Oncology, Poznań University of Medical Sciences, 60-569 Poznań; \\ ${ }^{8}$ Department of Lung Diseases with Oncology Subdivision, Mazovian Center for the Treatment of \\ Lung Diseases and Tuberculosis, 60-569 Otwock; ${ }^{9}$ Department of Oncology, Provincial Hospital Center of \\ The Jeleniogórska Valley, 58-506 Jelenia Góra; ${ }^{10}$ Department of Clinical Oncology, \\ Independent Public Provincial Hospital Pope John Paul II in Zamość, 22-404 Zamość; \\ ${ }^{11}$ Department of Oncology, Chemotherapy Subdivision, Independent Public Group of Tuberculosis and \\ Pulmonary Diseases in Olsztyn, 10-357 Olsztyn; ${ }^{12}$ Department of Clinical Oncology and Chemotherapy, and \\ ${ }^{13}$ Chair and Department of Thoracic Surgery, Pomeranian Medical University, 70-891 Szczecin, Poland
}

Received November 4, 2020; Accepted January 14, 2021

DOI: $10.3892 / \mathrm{ol} .2021 .12710$

\begin{abstract}
Anti-programmed death-1 or anti-programmed death-ligand 1 (PD-L1) blockade may be ineffective in some patients with non-small cell lung cancer (NSCLC) with high percentage of tumor cells with PD-L1 expression. In addition, immunotherapy may provide great benefits in patients without PD-L1 expression. The present study assessed PD-L1 protein expression by immunohistochemistry, copy number variation $(\mathrm{CNV})$ of $P D-L 1$ and two single nucleotide
\end{abstract}

Correspondence to: Dr Anna Grenda, Chair and Department of Pneumology, Oncology and Allergology, Medical University of Lublin, 8 Jaczewskiego, 20-090 Lublin, Poland

E-mail: an.grenda@gmail.com

Key words: programmed death-ligand 1, non-small cell lung cancer, protein expression, single nucleotide polymorphism, copy number variation polymorphisms (SNPs), rs822335 and rs822336, in the promoter of $P D-L 1$ by quantitative PCR in 673 patients with NSCLC. Overall survival time of patients with NSCLC depending on the assessed predictive factors ( $P D-L 1 \mathrm{CNV}$ or SNP) and the treatment methods (immunotherapy in first/second line of treatment or chemotherapy) was analyzed. The present study revealed significantly higher $P D-L 1$ copies number in patients with $\geq 10 \%$ and $\geq 50 \%$ of tumor cells with PD-L1 expression compared to patients with lower percentage of PD-L1-positive tumor cells $(\mathrm{P}=0.02$ and $\mathrm{P}=0.0002$, respectively). There was a significant positive correlation $(\mathrm{R}=0.2 ; \mathrm{P}=0.01)$ between number of PD-L1 copies and percentage of tumor cells with PD-L1 protein expression. Percentage of tumor cells with PD-L1 expression was lower in patients with TT genotype of the rs822335 polymorphism compared to those with CC genotype $(\mathrm{P}=0.03)$. The present study observed significantly higher risk of death in patients treated with chemotherapy compared to those treated with immunotherapy $(\mathrm{P}<0.0001$; hazard ratio $=2.4768 ; 95 \%$ confidence interval, 2.0120-3.0490). The present study demonstrated a close relationship between 
$P D-L 1$ copies number, genotype of rs $822335 P D-L 1$ polymorphism and PD-L1 protein expression on tumor cells. However, the impact of CNV and SNPs of $P D-L 1$ on overall survival of patients with NSCLC requires further investigation.

\section{Introduction}

Lung cancer (LC) is one of the most common causes of death in the world and is the cause of $20 \%$ of cancer-associated deaths (1). The incidence of LC in Europe is $>410,000$ cases/year (1-3). Occurrence of LC is in second place $(>200,000$ cases/year in Europe) in men after prostate cancer and third in women $(\sim 100,000$ cases/year) after breast and colorectal cancer (2). Non-small cell LC (NSCLC) is the most frequent histopathological type of LC ( $\sim 85 \%$ of all LC cases) (3). At present, the most effective therapeutic option for NSCLC seems to be immunotherapy targeting immune checkpoints (4). One of these checkpoints involves programmed death-ligand 1 (PD-L1); PD-L1 expression on neoplastic cells allows them to escape from immune surveillance by interacting with programmed death-1 (PD-1) located on T cells $(4,5)$. Immunotherapies using anti-PD-1 or anti-PD-L1 monoclonal antibodies block the PD-1/PD-L1 pathway and make cancer cells visible to the immune system, which can now recognize and destroy them $(4,5)$. Suitability for immunotherapy is based on the evaluation of protein expression on tumor cells using immunohistochemical methods (4-7).

Examination of PD-L1 expression using immunohistochemistry (IHC) serves an important role in the qualification of patients with NSCLC for first line immunotherapy (6-10). Patients with PD-L1 expression on $\geq 50 \%$ of tumor cells may be treated with first line pembrolizumab therapy $(6,7)$. Currently, monoclonal antibodies clone 22C3 (DAKO) or clone SP263 (Ventana) are recommended for assessing PD-L1 expression on tumor cells (TCs) (8). However, five different antibody clones (SP142, SP263, 22C3, 28-8, 73-10) and IHC tests were used for assessment of PD-L1 expression in clinical trials with different anti-PD-1 or anti-PD-L1 immune-check points inhibitors (such as nivolumab, pembrolizumab and durvalumab) (9-12). These resulted in divergent evaluation of PD-L1 expression on tumor and immune cells $(9,10)$. From a technical point of view, the differences in IHC tests results are due to the different affinity strength of particular antibodies and due to their different binding site in PD-L1 molecule (extracellular or intracellular domain of PD-L1 protein) $(11,12)$. The expression of PD-L1 protein on cancer cells may also depend on $P D-L 1$ expression, single nucleotide polymorphisms (SNPs) or the number of $P D$ - $L 1$ copies [copy number variation $(\mathrm{CNV})]$.

There are several SNPs of $P D-L 1$ described in literature, such as rs2297136, rs4143815, rs4143815, rs822336 or rs822337 (13-22). They have different locations in the gene (introns, exons, promoters), however majority of them are located in 3'-untranslated region (3'-UTR) and are closely related to posttranscriptional regulation of gene expression (related to microRNA activity) (15-22). There is some evidence that $P D-L 1$ polymorphisms may be independent predictive biomarkers in patients with NSCLC receiving first-line chemotherapy with paclitaxel and cisplatin (15). Studies on $P D$ - $L 1$ polymorphisms are conducted mainly in Asian populations $(15,16)$. The promoter region is involved in the initial regulation of gene expression (transcription). Specific transcription factors, recognizing the promoter sequence, attach and recruit other proteins, including polymerases involved in transcription initiation. Therefore, the sequence of promoter region is crucial for the attachment of proteins, and polymorphisms of the promoter region may affect the binding strength of transcription complex, which may change PD-L1 expression (23).

The CNV of different genes is another genetic factor affecting protein expression. Some studies have indicated that the number of $P D-L 1$ copies detected by fluorescence in-situ hybridization (FISH) or quantitative (q)PCR is associated with PD-L1 protein expression detected using IHC, which is the only method approved in daily practice to assess PD-L1 expression in qualifying patients for immunotherapy (24-29). qPCR is a simpler method compared with FISH for assessing $P D-L 1$ copies number. However, correlation between PD-L1 protein expression and $P D-L 1$ copies number has not always been statistically significant using these two methods $(26,27)$.

Currently, IHC for assessing PD-L1 expression on TCs is the gold standard in qualification of patients with NSCLC to first-line immunotherapy $(11,14,24)$. However, anti-PD-1 or anti-PD-L1 blockade may be ineffective in some patients with NSCLC with high percentage of TCs with PD-L1 expression $(10,11,25)$. In addition, immunotherapy may provide great benefits in patients without expression of this protein $(10,11,25)$. Moreover, to the best of our knowledge, there are no clinical trials comparing the efficacy of the first-line of immunotherapy used in patients with a high percentage of PD-L1-positive TCs to the second-line of immunotherapy used after first-line chemotherapy, regardless of the status of PD-L1 expression on TCs. It may be that both methods of treatments have similar effect on overall survival (OS) of patients with NSCLC $(10,11,14,24,25)$. This may suggest that PD-L1 expression on TCs is a useful marker in qualification of patients to first-line immunotherapy, but may not be predictive of OS in patients treated with first- or second-line immunotherapy. Hence, the present study investigated the molecular background of PD-L1 expression on TCs in a large group of Caucasian patients with NSCLC and aimed to identify new, potential predictive factors for immunotherapy. In addition, the present study assessed the effect of selected predictive factors and the type of treatment [best supportive care (BSC), 1st, and 2nd line of immunotherapy] on OS in patients with NSCLC.

\section{Materials and methods}

Studied group. A total of 673 locally advanced or advanced patients with NSCLC without epidermal growth factor receptor $(E G F R)$ gene mutations and anaplastic lymphoma kinase $(A L K)$ gene rearrangement were enrolled. The present study was a multicenter study, and materials were collected between March 2017 and February 2019 at the following centers: Independent Public Clinical Hospital No. 4 (Lublin, Poland), Saint John of Dukla Oncology Centre of the Lublin Region (Lublin, Poland), Specialist Hospital for Lung Diseases (Zakopane, Poland), Poland Lord's Transfiguration Clinical Hospital (Poznań, Poland), Mazovian Center for the Treatment of Lung Diseases and Tuberculosis (Otwock, Poland), 
Provincial Hospital Center of the Jeleniogórska Valley (Jelenia Góra, Poland), Independent Public Provincial Hospital Pope John Paul II (Zamość, Poland), Independent Public Group of Tuberculosis and Pulmonary Diseases (Olsztyn, Poland) and Regional Hospital for Lung Diseases (Szczecin-Zdunowo, Poland). The mean age of the patients was $67 \pm 7.7$ years (age range, 36-88 years). There were 428 (64\%) male and 245 (36\%) female patients. The patients provided written consent prior to enrollment in the study. The study was approved by the Ethics Committee of the Medical University of Lublin(Lublin, Poland) (approval no. KE-0254/95/2018). Adenocarcinoma (AC) was diagnosed in 370 patients $(55 \%)$, squamous cell carcinoma (SqCC) in 266 patients (40\%), large cell carcinoma (LCC) in 9 patients (1\%) and NSCLC not otherwise specified (NOS) in 28 patients (4\%). Genetic and IHC assays were performed in formalin-fixed paraffin-embedded (FFPE) tissue specimens (476; $71 \%$ cases) or in cell blocks $(197 ; 29 \%$ cases $)$ obtained via routine hospital procedures. FFPE material was prepared from forceps biopsy carried out during bronchoscopy or from surgical materials, while cell blocks were prepared mostly from materials obtained in endobronchial ultrasound transbronchial needle aspiration (EBUS-TBNA) or endoscopy ultrasound fine-needle aspiration (EUS-FNA) procedures. 499 samples were primary tumor, while 174 were lymph node metastases or distant metastases. Data on methods of treatment and overall survival were available for 662 patients, who were included in the study. In the studied group, 131 (20\%) patients received immunotherapy as one of the treatment lines (as first-line therapy or after chemotherapy) and 489 (73\%) patients only chemotherapy. A total of $42(6 \%)$ patients did not receive any systemic treatment. Of the immunotherapy group, a total of $57(44 \%)$ patients received pembrolizumab as first-line therapy and $74(56 \%)$ patients received atezolizumab or nivolumab in the second-line of treatment. A total of 44 of the aforementioned patients had the second-line of chemotherapy after pembrolizumab failure and 46 patients had the third-line of chemotherapy after failure of atezolizumab or nivolumab. OS time was calculated from diagnosis to death or last observation. Median follow-up was 24 months, with follow-up performed on the basis of patients' visits to the hospital, analysis of data from the medical system and telephone information.

$I H C$. Analysis of PD-L1 protein expression was performed on FFPE or cell block materials cut into $3-\mu \mathrm{m}$-thick sections. These were put on Thermo Scientific Superfrost Plus ${ }^{\mathrm{TM}}$ (Thermo Fisher Scientific, Inc.) glass slides and preheated at $59^{\circ} \mathrm{C}$ on a hotplate for at least $3 \mathrm{~h}$ prior to staining. The Ventana PD-L1 clone SP263 antibody (1.61 $\mu \mathrm{g} / \mathrm{ml}$; cat. no. 790-4905; Ventana Medical Systems, Inc.; Roche Diagnostics) was used as a primary antibody for PD-L1 protein IHC staining. IHC was performed using automated Ventana Benchmark GX equipment (Ventana Medical Systems, Inc.; Roche Diagnostics) according to the manufacturer's instructions in a closed, fixed programme. OptiView DAB IHC detection kit (Ventana Medical Systems, Inc.; Roche Diagnostics) was used as a detection system. Counterstaining using hematoxylin II (Ventana Medical Systems, Inc.; Roche Diagnostics), was included in the staining protocol. Rabbit monoclonal negative control immunoglobulin $(10 \mu \mathrm{g} / \mathrm{ml}$; cat. no. 790-4795; Ventana Medical Systems, Inc.; Roche Diagnostics) was used as a negative control. After staining all glass slides were washed and dehydrated in a series of $296 \%$ ethanol and 2 xylene washing steps and then cover-slipped. Next, the slides were assessed by 2 pathologists (Medical University of Lublin, Lublin, and Specialist Hospital for Lung Diseases 'Rebirth' Klara Jelska, Zakopane; Poland) using an Olympus BX41 light microscope. The assessment was based on whole stained slide analysis, with at least 50 viable TCs available. The percentage of PD-L1 positive TCs was determined according to the presence or absence of staining of TCs, under consecutive magnifications (from $x 40$ to $x 400$ ) depending on the intensity of the staining. Comparison of corresponding haematoxylin and eosin (H\&E) and PD-L1 IHC slides was made to make sure the material had enough TCs to get a proper diagnosis.

DNA extraction. Genomic DNA (gDNA) was isolated from FFPE and cell blocks using QIAamp DNA FFPE Tissue kit (Qiagen $\mathrm{GmbH}$ ) according to the manufacturer's instructions. The quality and quantity of DNA was assessed using BioPhotometer UV/Vis Spectrophotometer (Eppendorf). The quality (ratio 260/280) of the isolates was 1.7-2.0 and the concentration was in the range $20-192 \mathrm{ng} / \mu \mathrm{l}$.

qPCR. A total of 2 polymorphisms, rs822335 (C_7590674_10; cat. no. 4351379; Applied Biosystems; Thermo Fisher Scientific, Inc.) and rs822336 (C_1348559_10; cat. no. 4351379; Applied Biosystems; Thermo Fisher Scientific, Inc.) in the PD-L1 promoter region were studied. In the present study, 2 SNPs of PD-L1 promoter region were selected from the PubMed dbSNP database (https://www.ncbi.nlm.nih.gov/snp/). PCR mixture contained: $5.5 \mu \mathrm{l}$ of Genotyping MasterMix (Applied Biosystems; Thermo Fisher Scientific, Inc.), $4 \mu 1$ of aforementioned gDNA $(5 \mathrm{ng} / \mu \mathrm{l})$ and $0.5 \mu \mathrm{l}$ of TaqMan SNP Assay (Applied Biosystems; Thermo Fisher Scientific, Inc.). The following conditions were used for denaturation and enzyme activation: $95^{\circ} \mathrm{C}$ for $10 \mathrm{~min}$, and 40 cycles of $95^{\circ} \mathrm{C}$ for $15 \mathrm{sec}$ and $62^{\circ} \mathrm{C}$ for $60 \mathrm{sec}$.

CNV of $P D-L 1$ were studied by qPCR using TaqMan ${ }^{\mathrm{TM}}$ Copy Number Assay (Hs03704252_cn; cat. no. 4400291; Applied Biosystems; Thermo Fisher Scientific, Inc.) and RNazeP was used as a housekeeping gene (TaqMan $^{\text {TM }}$ Copy Number Reference Assay; cat. no. 4403326; Applied Biosystems; Thermo Fisher Scientific, Inc.). CNV was scored using the $2^{-\triangle \Delta \mathrm{Cq}}$ method (28). The thermocycling conditions were as follows: $10 \mathrm{~min}$ initial denaturation at $95^{\circ} \mathrm{C}$ followed by 40 cycles of $95^{\circ} \mathrm{C}$ for $15 \mathrm{sec}$ and $62^{\circ} \mathrm{C}$ for $90 \mathrm{sec}$. qPCR was performed on Illumina Eco Real-Time PCR equipment (Illumina, Inc.). Each qPCR reaction was performed in duplicate.qPCR results were analyzed using the EcoStudy-v4.0.4420 software (Illumina, Inc.). Three copies of $P D-L 1$ were adopted as an exponent of abnormal amplification.

Statistical analysis. Statistical analysis was carried out using Statistica 13.1 (TIBCO Software, Inc.) and MedCalc (MedCalc Software bvba) softwares. The data were presented as the mean $\pm \mathrm{SE}$. Each $\mathrm{qPCR}$ reaction was performed in duplicate. The unpaired Student's t-test was used to assess the differences in means of $P D-L 1$ copies number and percentage of tumor cells with PD-L1 expression in groups of patients with different SNPs and clinical factors. Associations between 
A

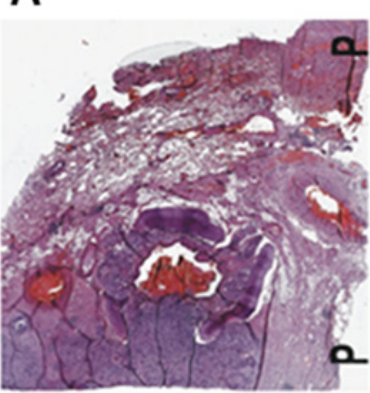

D

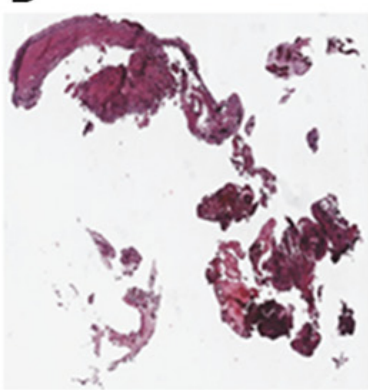

G

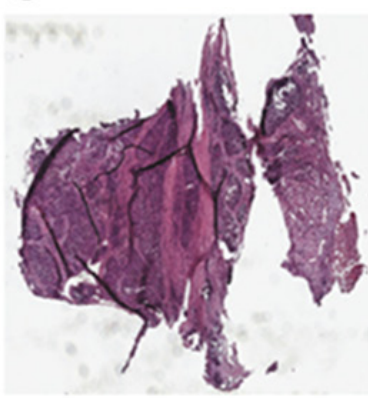

B

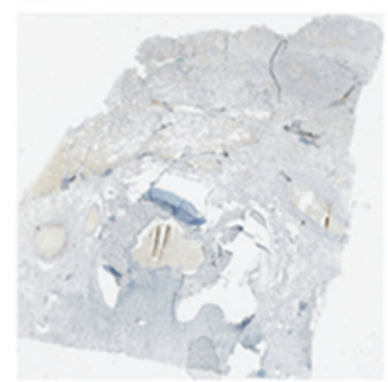

$E$

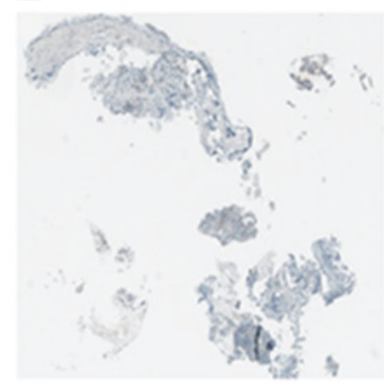

H

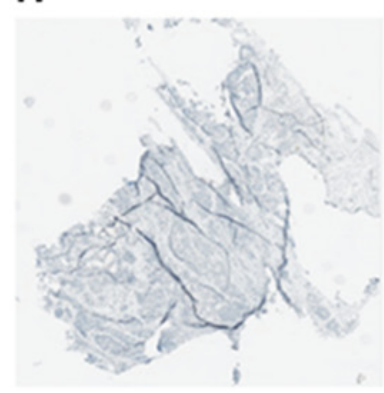

C

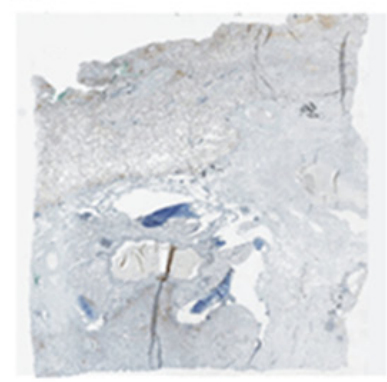

$\mathbf{F}$

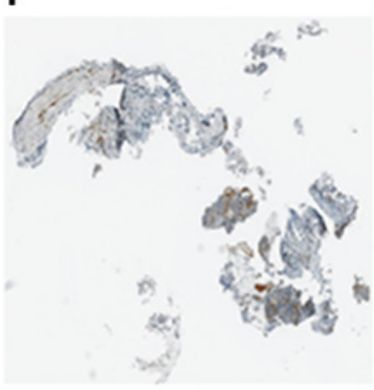

I

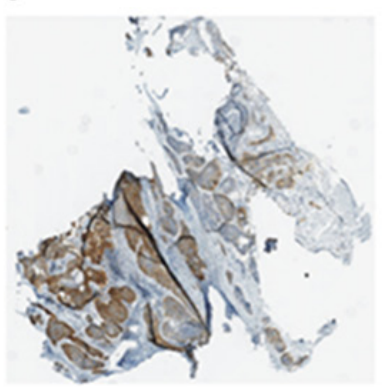

Figure 1. Examples of the evaluation of PD-L1 protein expression on TCs (magnification, x8). Case 1 (A) H\&E staining, (B) control staining (negative) and (C) PD-L1 expression on $1 \%$ of TCs. Case 2 (D) H\&E staining, (E) control staining (negative) and (F) PD-L1 expression on 10\% of TCs. Case 3 (G) H\&E staining, (H) control staining (negative) and (I) PD-L1 expression on 50\% of TCs. PD-L1 protein expression (in formalin-fixed paraffin-embedded or cell block materials cut into 3- $\mu \mathrm{m}$-thick sections put on Thermo Scientific Superfrost Plus ${ }^{\mathrm{TM}}$ glass slides and preheated at $59^{\circ} \mathrm{C}$ on a hotplate for $\geq 3$ h prior to staining) was assessed using the Ventana PD-L1 clone SP263 antibody. IHC was performed on Ventana Benchmark GX equipment according to the manufacturer's instructions in a closed, fixed programme. PD-L1, programmed death-ligand 1; H\&E, hematoxylin and eosin; TCs, tumor cells.

genotypes of $P D-L 1$ and clinical factors, as well as PD-L1 CNV and protein expression were examined using the Fisher's exact test. Correlation between percentage of tumor cells with PD-L1 expression and PD-L1 CNV was assessed using the Spearman correlation test. The Kaplan-Meier log-rank method was used to analyze the OS time for patients with different predictive factors: type of treatment, line of immunotherapy, percentage of PD-L1-positive tumor cells, CNV and SNPs of $P D-L 1 . \mathrm{P}<0.05$ was considered to indicate a statistically significant difference.

\section{Results}

PD-L1 protein expression analysis. In the entire patient group, mean percentage of tumor cells with PD-L1 expression was $25 \pm 30 \%$. The patients were divided according to PD-L1 expression into 5 groups: i) Patients without PD-L1 expression ( $0 \%$ of TCs with PD-L1 expression, group 1); ii) patients with any PD-L1 expression ( $\geq 1 \%$ of PD-L1 positive tumor cells, group 2); iii) patients with $\geq 5 \%$ of PD-L1 positive TCs (group 3); iv) patients with $\geq 10 \%$ of PD-L1 positive TCs (group 4); and v) patients with $\geq 50 \%$ of PD-L1 positive TCs (group 5). Group 1 consisted of 162 (24\%) patients; group 2, 511 patients $(76 \%)$; group 3,440 patients $(65 \%)$; group 4 , $355(53 \%)$ and group 5, 169 (25\%) patients (Table I). Table I presents the characteristics of patients from groups with different percentage of tumor cells with PD-L1 expression. Fig. 1 shows IHC staining results of single patients from the groups described above.

A significantly higher percentage of patients with any expression of PD-L1 on TCs was observed in the SqCC group compared with the AC group $\left(\chi^{2}=18.039 ; \mathrm{P}=0.0002\right.$; Table I $)$. In addition, it was also observed that the presence of PD-L1 expression on $\geq 10 \%$ of TCs was significantly more frequent in FFPE materials compared to cellblocks $\left(\chi^{2}=4.088 ; \mathrm{P}=0.043\right.$; Table I). Tissue from primary tumors (most commonly obtained by forceps biopsy or surgical resection) had significantly higher expression of PD-L1 on $\geq 1 \%$ and $\geq 50 \%$ of TCs compared with materials obtained from lymph node metastases (most commonly obtained by EBUS-TBNA, EUS-FNA or other 


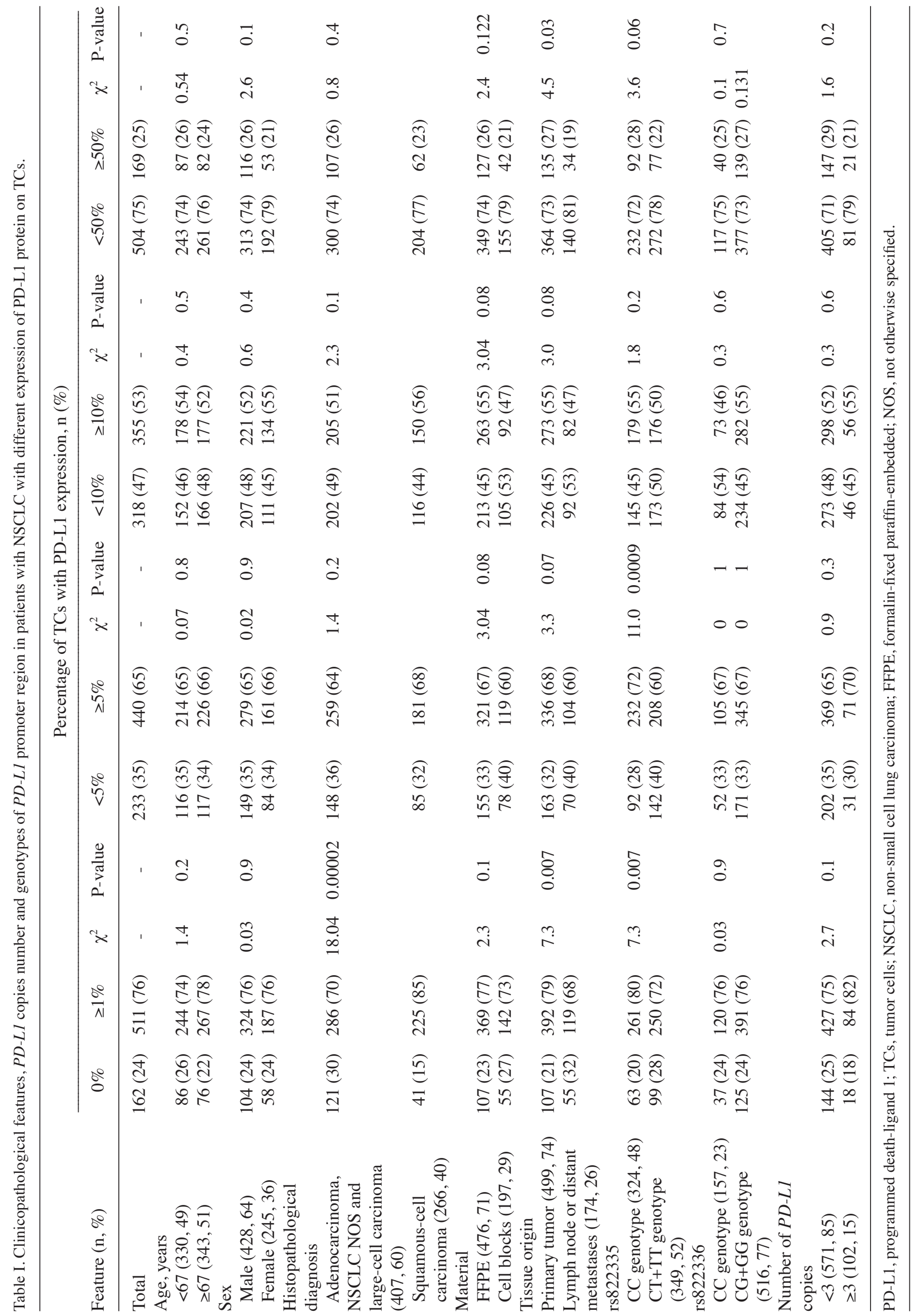


Table II. Clinicopathological and demographic features of patients according to $P D-L 1$ copy number variant.

\begin{tabular}{|c|c|c|c|c|}
\hline Feature $(n, \%)$ & $<3$ copies, $\mathrm{n}(\%)$ & $\geq 3$ copies, $\mathrm{n}(\%)$ & $\chi^{2}$ & P-value \\
\hline Total & $571(85)$ & $102(15)$ & - & - \\
\hline \multicolumn{5}{|l|}{ Sex } \\
\hline Male $(428,64)$ & $360(81)$ & $68(19)$ & 0.49 & 0.48 \\
\hline Female $(245,36)$ & $211(86)$ & $34(14)$ & & \\
\hline \multicolumn{5}{|l|}{ Histopathological diagnosis } \\
\hline Adenocarcinoma, NSCLC NOS and large-cell carcinoma $(407,60)$ & $356(87)$ & $51(13)$ & 5.51 & 0.02 \\
\hline Squamous cell carcinoma $(266,40)$ & $215(81)$ & $51(19)$ & & \\
\hline \multicolumn{5}{|l|}{ Tissue origin } \\
\hline Primary tumor $(499,74)$ & $424(85)$ & $75(15)$ & 0.29 & 0.59 \\
\hline Lymph node or distant metastases $(174,26)$ & $147(84)$ & $27(16)$ & & \\
\hline \multicolumn{5}{|l|}{ Material } \\
\hline FFPE $(476,71)$ & $405(85)$ & $71(15)$ & 0.07 & 0.79 \\
\hline Cell blocks $(197,29)$ & $166(84)$ & $31(16)$ & & \\
\hline
\end{tabular}

PD-L1, programmed death-ligand 1; NSCLC, non-small cell lung carcinoma; FFPE, formalin-fixed paraffin-embedded; NOS, not otherwise specified.
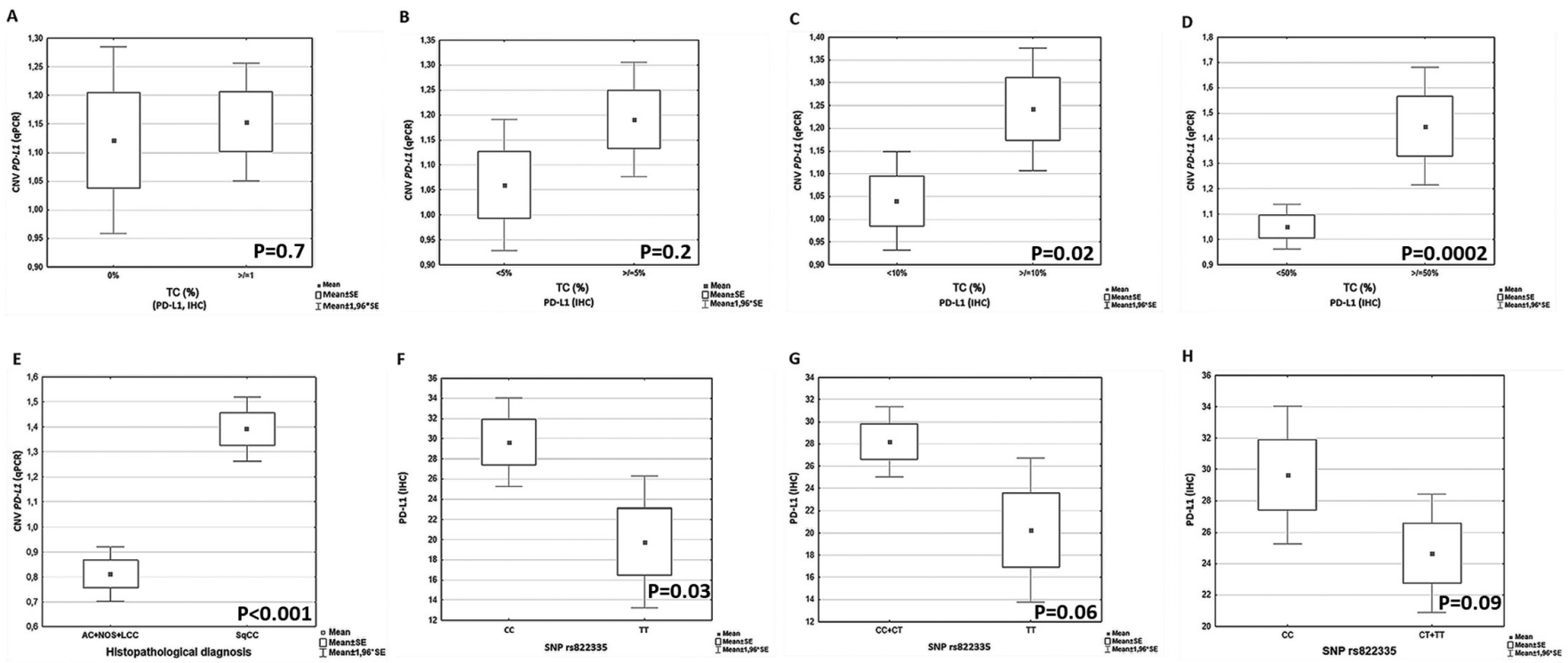

Figure 2. Analysis of the relationship between $P D-L 1$ copies number and percentage of TCs expressing PD-L1 protein. Relationship between CNV and percentage of TCs with PD-L1 expression: (A) 0 vs. $\geq 1 \%$, (B) $<5$ vs. $\geq 5 \%$, (C) $<10$ vs. $\geq 10 \%$ and (D) $<50$ vs. $\geq 50 \%$ TCs with PD-L1 expression. (E) Relationship between CNV and histopathological diagnosis. Relationship between TCs with PD-L1 expression and allelic variants of rs822335: (F) CC vs. TT, (G) CC+CT vs. TT and (H) CC vs. CT+TT. PD-L1, programmed death-ligand 1; TCs, tumor cells; CNV, copy number variant; SNP, single nucleotide polymorphism; IHC, immunohistochemistry; q, quantitative; AC, adenocarcinoma; NOS, not otherwise specified; LCC, large cell carcinoma; SqCC, squamous cell carcinoma.

fine-needle aspiration procedures $)\left(\chi^{2}=7.296 ; \mathrm{P}=0.007\right.$ and $\chi^{2}=4.506 ; \mathrm{P}=0.034$, respectively; Table I). In conclusion, the aforementioned results demonstrated that histological materials are more relevant for the analysis of PD-L1 expression compared with materials from EBUS-TBNA or EUS-FNA.

CNV of $P D-L 1$. The present study found that in $571(85 \%)$ cases, $P D-L 1$ copies number was $<3$ copies and in $102(15 \%)$ cases it was $\geq 3$. Tables I and II were generated to characterize groups of patients with different $P D-L 1$ copies number. It was demonstrated that $P D-L 1$ amplification was more common in patients with $\mathrm{SqCC}$ compared with patients with other types of
NSCLC $\left(\chi^{2}=5.51 ; \mathrm{P}=0.02\right.$; Table II $)$. In addition, significantly higher number of $P D-L 1$ copies in were demonstrated in SqCC compared with AC, NSCLC NOS, or LCC ( $\mathrm{P}<0.01$; Fig. $2 \mathrm{E})$.

A significant positive correlation was found between $P D-L 1$ copies number and percentage of TCs with PD-L1 protein expression $(\mathrm{R}=0.2 ; \mathrm{P}=0.01$; data not shown). No significant differences in number of $P D-L 1$ copies between groups of patients with $0 \%$ and any percentage of tumor cells with PD-L1 expression were found ( $\mathrm{P}=0.7$; Fig. $2 \mathrm{~A}$ ), as well as between groups of patients with $<5 \%$ and $\geq 5 \%$ of tumor cells with PD-L1 expression ( $\mathrm{P}=0.2$; Fig. $2 \mathrm{~B})$. However, a significantly higher number of $P D-L 1$ copies were observed 
Table III. Clinicopathological and demographic features of patients according to rs822335 genotype.

\begin{tabular}{|c|c|c|c|c|c|}
\hline Feature $(\mathrm{n}, \%)$ & $\mathrm{CC}, \mathrm{n}(\%)$ & $\mathrm{CT}, \mathrm{n}(\%)$ & $\mathrm{TT}, \mathrm{n}(\%)$ & $\chi^{2}$ & P-value \\
\hline Total & $324(48)$ & $255(38)$ & $94(14)$ & - & - \\
\hline \multicolumn{6}{|l|}{ Sex } \\
\hline Male $(428,64)$ & $213(50)$ & $153(36)$ & $62(14)$ & \multirow[t]{2}{*}{2.29} & \multirow[t]{2}{*}{0.32} \\
\hline Female $(245,36)$ & $111(45)$ & $102(42)$ & $32(13)$ & & \\
\hline \multicolumn{6}{|l|}{ Histopathological diagnosis } \\
\hline $\begin{array}{l}\text { Adenocarcinoma, NSCLC NOS and } \\
\text { large-cell carcinoma }(407,60)\end{array}$ & $184(45)$ & $165(41)$ & $58(14)$ & \multirow[t]{2}{*}{4.34} & \multirow[t]{2}{*}{0.11} \\
\hline Squamous-cell carcinoma $(266,40)$ & $140(53)$ & $90(34)$ & $36(14)$ & & \\
\hline \multicolumn{6}{|l|}{ Tissue origin } \\
\hline Primary tumor $(499,74)$ & $249(50)$ & $184(37)$ & $66(13)$ & \multirow[t]{2}{*}{2.52} & \multirow[t]{2}{*}{0.28} \\
\hline Lymph node or distant metastases $(174,26)$ & $75(43)$ & $71(41)$ & $28(16)$ & & \\
\hline \multicolumn{6}{|l|}{ Material } \\
\hline FFPE $(476,71)$ & $243(51)$ & $171(36)$ & $62(13)$ & \multirow[t]{2}{*}{5.48} & \multirow[t]{2}{*}{0.06} \\
\hline Cell blocks $(197,29)$ & $81(41)$ & $84(43)$ & $32(16)$ & & \\
\hline
\end{tabular}

NSCLC, non-small cell lung carcinoma; FFPE, formalin-fixed paraffin-embedded; NOS, not otherwise specified.

A

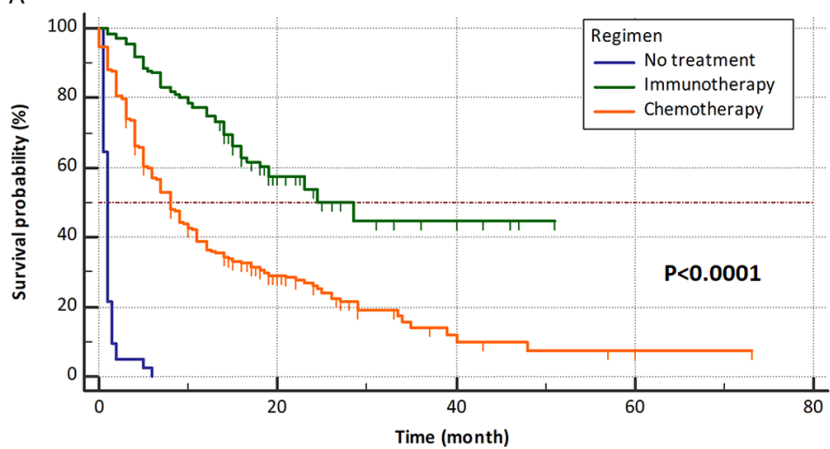

Number at risk

Group: No treatment

Group: Immunotherapy

Group: Chemotherapy

489

0
26
50

50
Time (month)

$\begin{array}{ll}0 & 0 \\ 4 & 0 \\ 5 & 1\end{array}$

B

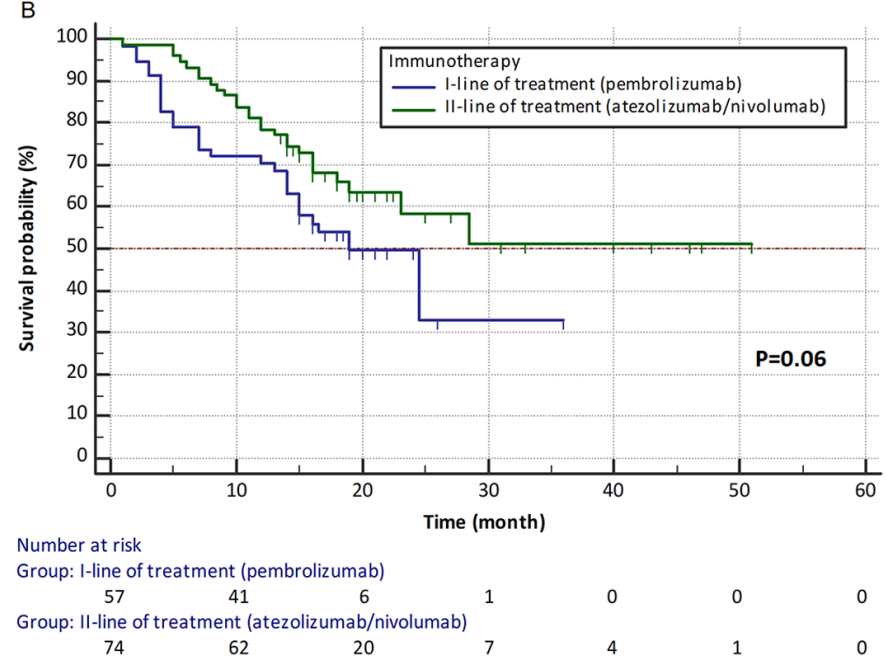

Figure 3. Kaplan- Meier curves of OS in patients with NSCLC. (A) Untreated, treated with immunotherapy or chemotherapy, (B) treated with first- or second-line immunotherapy. OS, overall survival; NSCLC, non-small cell lung carcinoma.

in groups of patients with $\geq 10 \%$ and $\geq 50 \%$ of PD-L1 positive cancer cells compared with groups of patients with $<10 \%$ and $<50 \%$ of tumor cells with PD-L1 expression ( $\mathrm{P}=0.02$ and $\mathrm{P}=0.0002$; Fig. $2 \mathrm{C}$ and $\mathrm{D}$, respectively). Differences in the analyzed parameters are also shown in Table I.

SNPS of PDL-1 gene promoter region. Tables I, III and IV represent the genotype distribution in the two analyzed SNPs in the studied group. The percentage of TCs with PD-L1 protein expression was significantly lower in group of patients with TT genotype in rs822335 compared with the CC genotype $(\mathrm{P}=0.03$; Fig. $2 \mathrm{~F})$. A trend of lower percentage of TCs with PD-L1 expression in group of patients with CT and TT genotypes were observed compared with patients with CC genotype in rs822335 ( $\mathrm{P}=0.09$; Fig. $2 \mathrm{H})$. Similarly, a slightly lower percentage of PD-L1 TCs was observed in carriers of TT genotype compared with patients with $\mathrm{CC}$ and $\mathrm{CT}$ genotypes rs822335 ( $\mathrm{P}=0.06$; Fig. 2G).

OS analysis. Median OS for the whole studied group was 9 months. Significantly higher risk of death was observed in patients treated with chemotherapy (median OS, 8 months) compared with those treated with any line immunotherapy (median OS, 28 months) $[\mathrm{P}<0.0001$; hazard ratio $(\mathrm{HR})=2.4768$; 95\% confidence interval (CI), 2.0120-3.0490; Fig. 3A]. In addition, a slightly greater risk of death in patients receiving first-line immunotherapy (median OS, 19 months) compared with those treated with second-line immunotherapy (median OS, 28 months) was observed $(\mathrm{P}=0.06$; $\mathrm{HR}=1.6834$; 95\% CI, 0.9697-2.9222; Fig. 3B). 
Table IV. Clinicopathological and demographic features of patients according to rs 822336 genotype.

\begin{tabular}{|c|c|c|c|c|c|}
\hline Feature $(\mathrm{n}, \%)$ & $\mathrm{CC}, \mathrm{n}(\%)$ & $\mathrm{CG}, \mathrm{n}(\%)$ & $\mathrm{GG}, \mathrm{n}(\%)$ & $\chi^{2}$ & P-value \\
\hline Total & $157(24)$ & $258(38)$ & $258(38)$ & - & - \\
\hline \multicolumn{6}{|l|}{ Sex } \\
\hline Male $(428,64)$ & $89(20)$ & $178(42)$ & $161(38)$ & \multirow[t]{2}{*}{6.64} & \multirow[t]{2}{*}{0.04} \\
\hline Female $(245,36)$ & $68(28)$ & $80(33)$ & $97(39)$ & & \\
\hline \multicolumn{6}{|l|}{ Histopathological diagnosis } \\
\hline $\begin{array}{l}\text { Adenocarcinoma, NSCLC NOS and } \\
\text { large-cell carcinoma }(407,60)\end{array}$ & $101(25)$ & $157(38)$ & $149(37)$ & \multirow[t]{2}{*}{1.79} & \multirow[t]{2}{*}{0.41} \\
\hline Squamous-cell carcinoma $(266,40)$ & $56(21)$ & $101(38)$ & $109(41)$ & & \\
\hline \multicolumn{6}{|l|}{ Tissue origin } \\
\hline Primary tumor $(499,74)$ & $118(23)$ & $193(39)$ & $188(38)$ & \multirow[t]{2}{*}{0.36} & \multirow[t]{2}{*}{0.83} \\
\hline Lymph node or distant metastases $(174,26)$ & $39(22)$ & $65(37)$ & $70(41)$ & & \\
\hline \multicolumn{6}{|l|}{ Material } \\
\hline FFPE $(476,71)$ & $110(23)$ & $186(39)$ & $180(38)$ & \multirow[t]{2}{*}{0.38} & \multirow[t]{2}{*}{0.83} \\
\hline Cell blocks $(197,29)$ & $47(24)$ & $72(36)$ & $78(40)$ & & \\
\hline
\end{tabular}

NSCLC, non-small cell lung carcinoma; FFPE, formalin-fixed paraffin-embedded; NOS, not otherwise specified.
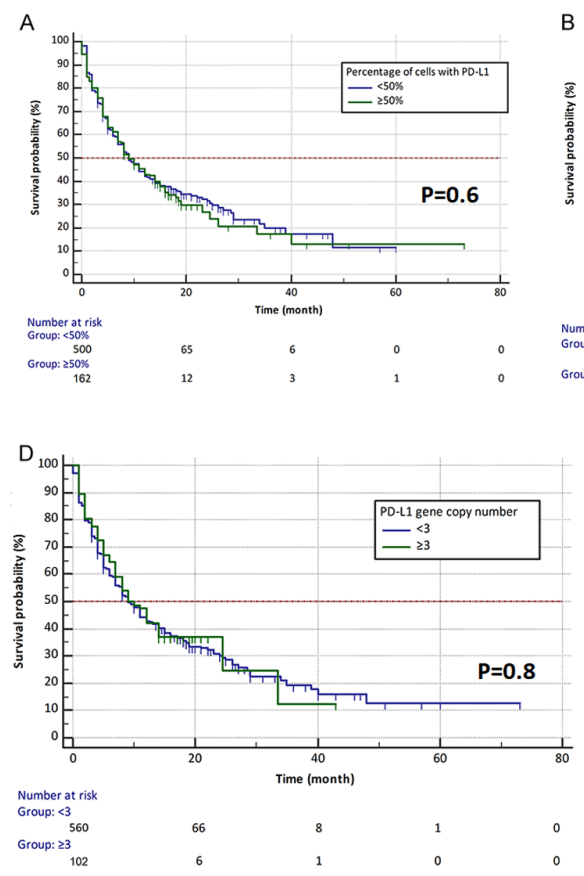

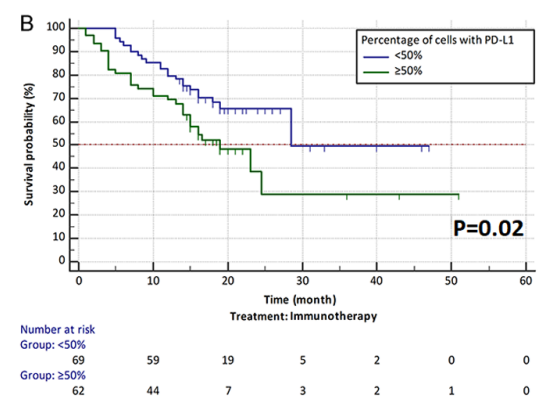

E
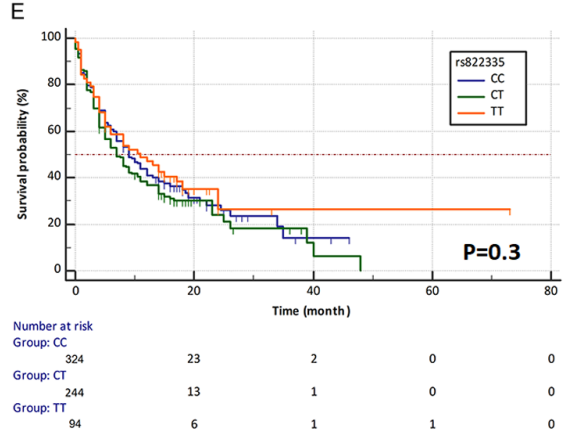
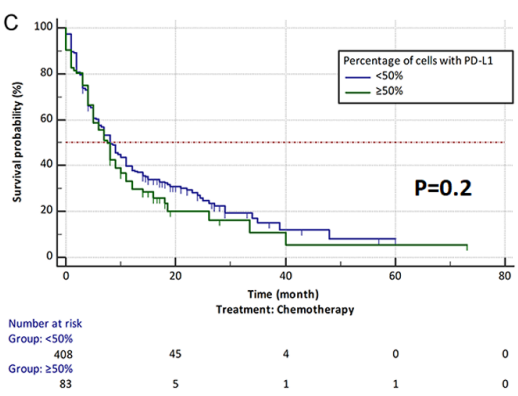

F

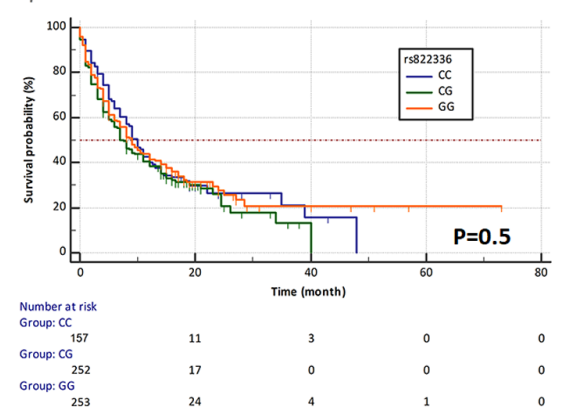

Figure 4. Kaplan-Meier curves of survival analysis in patients with NSCLC. According to percentage of TCs with PD-L1 expression (group with $\geq 50 \%$ PD-L1 positive TC vs. group with $<50 \%$ PD-L1 positive TC). (A) Entire cohort of patients, (B) immunotherapy treated patients, (C) patients who received chemotherapy. According to (D) $P D-L 1$ copies number, (E) genotype of the rs822335 polymorphism, (F) genotype of the rs822336 polymorphism. PD-L1, programmed death-ligand 1; TCs, tumor cells; NSCLC, non-small cell lung carcinoma.

There were no statistically significant differences in median OS between patients who had below and above $50 \%$ of PD-L1 positive TCs (median OS, 9 months; $\mathrm{P}=0.6$; Fig. 4A). However, in the group of patients treated with immunotherapy, patients with $\geq 50 \%$ PD-L1 positive tumor cells had greater risk of death compared with patients with $<50 \%$ tumor cells with PD-L1 expression ( $\mathrm{P}=0.02 ; \mathrm{HR}=1.9299,95 \%$ CI, 1.1221-3.3192; Fig. 4B). This relationship was probably due to the surprisingly greater effectiveness of second-line immunotherapy compared with first-line immunotherapy (only patients with $\geq 50 \%$ of tumor cells with expression of PD-L1 could receive pembrolizumab in the first-line therapy). There were no differences in median OS depending on percentage of TCs with PD-L1 expression in group of patients treated with chemotherapy $(\mathrm{P}=0.2$; Fig. 4C). No significant differences in risk of death in groups of patients with $P D-L 1$ copies number above and below 
3 were observed ( $\mathrm{P}=0.8$; Fig. 4D). No relationship was found between CNV of $P D-L 1$ and risk of death in both groups of patients receiving chemotherapy or immunotherapy. It was demonstrated that patients with the TT genotype in rs822335 polymorphism had only slightly higher median OS compared to patients with $\mathrm{CC}$ and $\mathrm{CT}$ genotypes $(\mathrm{P}=0.3$; Fig. 4E). This was particularly evident in patients receiving immunotherapy $(\mathrm{P}=0.1)$. Patients with different genotypes in rs822336 polymorphism treated with chemotherapy or immunotherapy had a similar risk of death $(\mathrm{P}=0.5$; Fig. $4 \mathrm{~F})$.

\section{Discussion}

Differences in DNA of cancer cells, such as SNPs and CNV, affect PD-L1 expression on tumor cells $(15,16,27,29,30)$. In the present study, 2 SNPs of $P D-L 1$ promoter region were selected from the PubMed dbSNP database (31). The results of the present study indicated that the rs 822335 polymorphism may be a predictor for PD-L1 protein expression on TCs in Caucasian patients with NSCLC. In the present study, the presence of $\mathrm{T}$ allele in rs 822335 polymorphism of $P D-L 1$ promoter was related to a lower percentage of TCs with PD-L1 protein expression, which confirmed our earlier on a smaller group of patients (29). In this previous study in 47 patients with NSCLC, CC genotype in rs 822335 predisposed to significantly higher percentage of TCs with PD-L1 expression tested with $22 \mathrm{C} 3$ antibody (29). In the present study, similar results were obtained with the use of the clone SP263 antibody. In addition, the present study to the best of our knowledge is one of the largest conducted in the world on this topic (673 patients). Most of the existing studies about SNPs in $P D-L 1$ have been conducted in Asian populations (15-17). In addition, a significant part of studied polymorphisms is located in the $3^{\prime}$ UTR of $P D-L 1$ (16).

Large studies of the impact of $P D-L 1$ polymorphisms on $\mathrm{PD}-\mathrm{L} 1$ protein expression and on prognosis in patients with NSCLC have been conducted by Ma et al (16) and Lee et al (17). Ma et al (16) analyzed SNPs in genes coding the immune-check point proteins [Cytotoxic T-Lymphocyte Associated Protein 4 (CTLA-4), PD-1 and PD-L1] in 528 patients with NSCLC and in 600 healthy people. Using PCR-RFLP (restriction fragments length polymorphism) method, the aforementioned study demonstrated that the distribution of polymorphic variants of CTLA-4 and $P D-1$ genes in the group of patients with NSCLC and healthy volunteers was similar (16). However, the incidence of AC genotype and the presence of $\mathrm{C}$ allele in rs 2890658 polymorphism of $P D-L 1$ was significantly higher in patients with NSCLC compared with healthy subjects (16). In addition, the $\mathrm{C}$ allele was more common in smokers compared with non-smokers (16). Further analysis indicated that this allele increased the risk of lymph node metastases (16). Studies suggested that the CC genotype in rs2890658 polymorphism may have a significant impact on the development and progression of $\operatorname{NSCLC}(16,20,22)$.

In 2017, Lee et al (17) presented an analysis of SNPs of $P D-L 1$ in 354 patients with early stage NSCLC. The occurrence of different alleles in rs822336, rs822337 and rs4143815 (the first 2 SNPs are located in the promoter and the third in the 3'UTR of $P D-L 1$ ) affected OS of patients NSCLC (11). In addition, they demonstrated that low mRNA expression of $P D-L 1$ was a negative prognostic factor for patients with NSCLC (17). The luciferase test in the aforementioned study demonstrated that the presence of the $\mathrm{G}$ allele in rs 4143815 provided lower transcription activity of $P D-L 1$ compared with $C$ nucleotide (17). In addition, the presence of $C$ allele in rs822336 and A allele in rs822337 decreased promoter activity compared with the presence of $\mathrm{G}$ allele in rs822336 and $\mathrm{T}$ allele in rs822337 polymorphism of $P D-L 1$ (17). However, no significant correlation was observed between the relative mRNA expression (measured by qPCR) for $P D-L 1$ and the rs4143815, rs822336 and rs822337 polymorphisms (17). The results presented by Lee et al (17) are consistent with the results of the present study, which demonstrated that the rs822336 polymorphism had no effect on PD-L1 expression on TCs.

In 2016, Lee et al (15) published a study on the relationship between 12 SNPs of $P D-1, P D-L 1$ and CTLA-4, and response to first-line chemotherapy (paclitaxel and cisplatin), and OS in 379 patients with advanced NSCLC. The rs2297136 polymorphism in the 3'UTR of $P D-L 1$ was significantly associated with response to chemotherapy and median OS. In addition, rs4143815 in the 3'UTR of the same gene was significantly associated with response to chemotherapy (15). The authors concluded that these SNPs may affect the expression of $P D-L 1$ as a result of modification of miR-324-5p, miR-570-3p binding site in 3'UTR of mRNA (9).

Du et al (18) also studied single nucleotide polymorphisms in the miR binding sites located in the 3'UTR of $P D-L 1$. They demonstrated that rs2297136 and rs4742098 polymorphisms were associated with risk of NSCLC, lymph node metastases, tumor invasion, and presence of distant metastases (18). In addition, they proved that both SNPs could influence the development of lung cancer through the changes in action of miR-296-5p, miR-138 and mRNA expression of $P D-L 1$ (18).

Yeo et al (19) investigated the prognostic value of rs 4143815 (3'UTR), rs822336 (promoter), rs822337 (promoter) polymorphisms of $P D-L 1$ in 147 patients with NSCLC. Examined group included $84 \mathrm{AC}$ patients and $63 \mathrm{SqCC}$ patients treated with chemotherapy (19). The aforementioned study used the pyrosequencing method for $P D-L 1$ genotyping. In $A C$ cases, the GG genotype of rs4143815 polymorphism was associated with shorter OS and progression free survival (PFS) compared with patients with other genotypes of this SNP. CC genotype in rs4143815 significantly increased PD-L1 expression on TCs detected by the $22 \mathrm{C} 3$ antibody (three clones of antibodies were used: SP142, 22C3 and SP263). No relationship between the genotype of rs 822336 and rs 822337 and the expression of $P D-L 1$ was observed (19). The results of the present study, regarding the rs 822336 polymorphism presented are consistent with the findings of the aforementioned study.

To the best of our knowledge, the present study demonstrated for the first time that patients with TT genotype of rs822335 polymorphism had slightly higher median OS compared with patients with $\mathrm{CC}$ and $\mathrm{CT}$ genotypes. This result is notable and interesting, as the findings of the present study also demonstrated that the presence of the TT genotype was associated with lower percentage of PD-L1 positive TCs compared with the CC variant in rs822335. The explanation for this phenomenon may be lower effectiveness of the first-line immunotherapy used in patients with PD-L1 
expression on $\geq 50 \%$ of TC compared with the second-line immunotherapy used in patients with lower percentage of PD-L1 positive TCs. Differences in effectiveness of first and second-line immunotherapy could explain why patients with PD-L1 expression in $\geq 50 \%$ of TC had slightly lower median OS compared with patients with $<50 \%$ of PD-L1 positive TCs in the present study. However, the findings of the present study require further investigation.

The higher effectiveness of immunotherapy over chemotherapy is beyond doubt $(7,24)$. This fact is confirmed by the results of the present study and the results of numerous clinical trials $(11,13,14,24,25)$. However, in clinical trials assessing the effectiveness of first-line immunotherapy compared with first-line chemotherapy, a number of patients after termination of chemotherapy received second-line immunotherapy (crossover). KEYNOTE-024 (7) and KEYNOTE-042 (24) studies compared the effectiveness of pembrolizumab versus platinum-based chemotherapy in patients with $\geq 50 \%$ or $\geq 1 \%$ of PD-L1 positive tumor cells, respectively. In KEYNOTE-024, median OS was 30 months for patients treated with pembrolizumab and 14 months in patients who received chemotherapy (7). For a subgroup of patients with $\geq 50 \%$ of PD-L1 positive TCs enrolled in KEYNOTE-042 study, there was also a significant benefit for pembrolizumab compared with chemotherapy (median OS, 20 vs. 12 months) (24). Percentage of patients receiving a subsequent PD-1 inhibitor after progression in chemotherapy arm was $65 \%$ in KEYNOTE-024 study and $20 \%$ in KEYNOTE-042 study $(7,24)$.

The median OS in patients receiving the second-line of immunotherapy is usually 10-12 months, which is calculated from the start of the second-line of immunotherapy $(7,24,25)$. The time from diagnosis to death should be calculated for estimation of OS of patients treated with chemotherapy followed by immunotherapy. Second-line immunotherapy usually begins 10-12 months after chemotherapy failure. Hence, OS calculated from the diagnosis in patients treated with chemotherapy with subsequent immunotherapy could reach 20-24 months. This would mean that first and second-line immunotherapy have comparable efficacy $(7,24,25)$. Of course, it is unacceptable to use first-line chemotherapy instead of immunotherapy in patients NSCLC with PD-L1 expression on $\geq 50 \%$ of tumor cells. The best systemic treatment should be used at the beginning of treatment. Numerous patients initially treated with chemotherapy after progression are not able to receive further treatment lines due to poor performance status. This phenomenon may also explain the longer median OS in patients treated with second-line immunotherapy compared with patients receiving first-line immunotherapy. These two groups of patients may have completely different clinical characteristics. Patients who receive two lines of treatment are still in good performance status and the course of the disease is usually slow. Progression (including hyperprogression) and deterioration of performance status in patients treated with pembrolizumab in the first-line of treatment could prevent the use of second-line chemotherapy. Hence, patients treated with the first-line pembrolizumab are patients who received only one treatment line $(7,24,25)$.

The present study demonstrated that $P D-L 1$ copies number was higher in the group of patients with a higher compared with a lower percentage of TCs with PD-L1 expression detected by the IHC method. In the present study, there was significant positive correlation between $P D-L 1$ copies number and percentage of TCs with PD-L1 expression. In addition, $P D-L 1$ copies number was higher in SqCC compared with ACC, NOS and LCC. This was consistent with the fact that PD-L1 expression detected by the IHC method was significantly more frequently found on TCs in patients with SqCC compared with patients with other types of NSCLC. However, the present study demonstrated that CNV of $P D-L 1$ was not a good marker for the estimation of OS in patients treated with immunotherapy, chemotherapy or BSC. Yoshimura et al (26) stated that the assessment of $P D-L 1$ copies number alterations provided more reproducible results than protein expression examination especially regarding intratumoral heterogeneity. The aforementioned study was performed in material from EBUS-TBNA of primary tumors, resected primary tumors and resected metastases. They used fluorescent in situ hybridization to score the CNV of $P D-L 1$ and a positive correlation between $P D-L 1$ copies number and PD-L1 protein expression in corresponding materials was found (26). CNV of $P D-L 1$ was less heterogeneous compared with protein expression in different parts of the tumor (26). Similarly, Inoue et al (27) examined differences in $P D-L 1$ copies number between primary tumors and synchronous regional lymph nodes metastases of patients with NSCLC. The aforementioned study revealed that the analysis of $C N V$ of $P D-L 1$ was highly consistent and reproducible compared with PD-L1 expression assessment. Inoue et al (27) also studied $P D-L 1 \mathrm{CNV}$ by FISH method in correlation with PD-L1 expression on tumor cells detected by the IHC method and demonstrated that there is a positive correlation between $P D-L 1 \mathrm{CNV}$ and protein expression on TCs. Both, high $P D-L 1$ copies number and high protein expression were predictors of poor survival in untreated patients (27). However, they postulated that increasing $P D-L 1$ copies number may be a feasible, alternative biomarker for prediction of response to anti-PD-1 or anti-PD-L1 antibodies (27).

The aforementioned studies used the FISH method for examination of $P D-L 1$ status in TCs $(26,27)$. The alternative to FISH method is qPCR method used for CNV of $P D$ - $L 1$ analysis by Ikeda et al (30) and the present study. Ikeda et al (30) examined 94 surgically resected lung cancer samples and found 5 samples (5\%) with $P D-L 1$ amplification. Patients with $P D-L 1$ amplification had poorer outcomes compared with patients with normal number of $P D-L 1$ (30). The aforementioned study adopted $3 P D-L 1$ copies as the cut-off threshold for recognition of $P D-L 1$ amplification (30). In the present study, amplification of $P D-L 1$ ( $\geq 3$ copies) was observed in $15 \%$ of patients with NSCLC. These discrepancies in percentage of patients with $P D-L 1$ amplification could result from the large size of patients' group analyzed in the present study. George et al (32) studied CNV of different genes in patients with small cell lung cancer using whole-genome sequencing and observed amplification of $P D-L 1$, which may indicate the sensitivity of small cell lung cancer patients to immune-check point blockade. The aforementioned study included a particularly important methodological approach, next generation sequencing and analyzed DNA and mRNA simultaneously (32), which is definitely a good approach enabling a deeper understanding of molecular background of tumor escape mechanisms from immune surveillance in the context of the implementation of immunotherapy in patients with lung cancer. 
The present study demonstrated that the expression of PD-L1 on tumor cells depends on extremely complex genetic mechanisms. The findings of the present study demonstrated that the rs822335 polymorphism and CNV of $P D-L 1$ influenced PD-L1 expression on TCs, but was not related to the OS of locally advanced or advanced patients with NSCLC. Of course, patients benefit from the use of immunotherapy instead of chemotherapy. The use of immunotherapy as the best first line of treatment depends on the presence of PD-L1 expression on $\geq 50 \%$ of tumor cells $(7,10,11)$. Unfortunately, not all patients treated with pembrolizumab in the first-line of treatment were able to receive a second-line of therapy in the present study. Therefore, a longer OS calculated from the time of diagnosis was recorded in patients treated with the second-line of immunotherapy in whom the percentage of TCs with PD-L1 expression was usually $<50 \%$. However, the present study presents some limitations. For example, analysis of PD-L1 mRNA expression and its epigenetic regulators should be further analyzed to provide additional information. Therefore, further studies should be performed to investigate the molecular background of PD-L1 expression and to identify additional predictive factors for immunotherapy.

\section{Acknowledgements}

Not applicable.

\section{Funding}

No funding was received.

\section{Availability of data and materials}

The datasets used and/or analysed during the current study are available from the corresponding author on reasonable request.

\section{Authors' contributions}

AG, PK, IC and TKuc conceived and designed the study. TKuc, KK, TKub, KR, DS, KS, RR, AB, BJ, JP, SF, JBu, ASi, AK, PS, JB1, JM, TG, RK and JS acquired the data. AG, TKuc, BJ, JP, IP and KK performed the experiments. AG, TKuc, $\mathrm{KK}, \mathrm{KR}, \mathrm{PK}$ and JBu were responsible for confirming the data authenticity. AG, BJ, ASz, JP, KL and MG analyzed and interpreted the data. $\mathrm{AG}, \mathrm{PK}$ and $\mathrm{KL}$ drafted the manuscript. $\mathrm{PK}, \mathrm{JBl}, \mathrm{RR}, \mathrm{TG}$ and $\mathrm{JM}$ revised the manuscript for important intellectual content. All authors have read and approved the manuscript.

\section{Ethics approval and consent to participate}

The study was approved by the Ethics Committee of the Medical University of Lublin (Lublin, Poland; approval no. KE-0254/95/2018). All patients provided written informed consent prior to being enrolled in the study.

\section{Patient consent for publication}

Not applicable.

\section{Competing interests}

The authors declare that they have no competing interests.

\section{References}

1. European Respiratory Society: European Lung White Book. Available from: www.erswhitebook.org/files/public/Chapters/ 19_lung_cancer.pdf. Accessed January 22, 2021.

2. Lung Cancer Europe: Report on Lung Cancer: Challenges in lung cancer in Europe. Available from: https://www.lungcancereurope.eu/wp-content/uploads/2017/10/LuCE-Report-final.pdf. Accessed January 22, 2021.

3. Navada S, Lai P, Schwartz AG and Kalemkerian GP: Temporal trends in small cell lung cancer: Analysis of the national Surveillance Epidemiology and End-Results (SEER) database. J Clin Oncol 24 (Suppl 18): 7082, 2006.

4. Bagley SJ, Bauml JM and Langer CJ: PD-1/PD-L1 immune checkpoint blockade in non-small cell lung cancer. Clin Adv Hematol Oncol 13: 676-683, 2015.

5. Iwai Y, Hamanishi J, Chamoto $\mathrm{K}$ and Honjo T: Cancer immunotherapies targeting the PD-1 signaling pathway. J Biomed Sci 24: 26, 2017.

6. Brahmer JR, Govindan R, Anders RA, Antonia SJ, Sagorsky S, Davies MJ, Dubinett SM, Ferris A, Gandhi L, Garon EB, et al: The Society for Immunotherapy of Cancer consensus statement on immunotherapy for the treatment of non-small cell lung cancer (NSCLC). J Immunother Cancer 6: 75, 2018.

7. Reck M, Rodríguez-Abreu D, Robinson AG, Hui R, Csőszi T, Fülöp A, Gottfried M, Peled N, Tafreshi A, Cuffe S, et al; KEYNOTE-024 Investigators: KEYNOTE-024 Investigators. Pembrolizumab versus chemotherapy for PD-L1-positive non-small-cell lung cancer. N Engl J Med 375: 1823-1833, 2016.

8. García A, Recondo G, Greco M, de la Vega M, Perazzo F, Recondo G, Avagnina A and Denninghoff V: Correlation between PD-L1 expression (clones 28-8 and SP263) and histopathology in lung adenocarcinoma. Heliyon 6: e04117, 2020.

9. Hirsch FR, McElhinny A, Stanforth D, Ranger-Moore J, Jansson M, Kulangara K, Richardson W, Towne P, Hanks D, Vennapusa B, et al: PD-L1 immunohistochemistry assays for lung cancer: Results from phase 1 of the Blueprint PD-L1 IHC Assay Comparison Project. J Thorac Oncol 12: 208-222, 2017.

10. Wojas-Krawczyk K, Kalinka E, Grenda A, Krawczyk P and Milanowski J: Beyond PD-L1-markers for lung cancer immunotherapy. Int J Mol Sci 20: E1915, 2019.

11. Vokes EE, Ready N, Felip E, Horn L, Burgio MA, Antonia SJ, Arén Frontera O, Gettinger S, Holgado E, Spigel D, et al: Nivolumab versus docetaxel in previously treated advanced non-small-cell lung cancer (CheckMate 017 and CheckMate 057): 3 -year update and outcomes in patients with liver metastases. Ann Oncol 29: 959-965, 2018.

12. Herbst RS, Baas P, Perez-Gracia JL, Felip E, Kim DW, Han JY, Molina JR, Kim JH, Dubos Arvis C, Ahn MJ, et al: Use of archival versus newly collected tumor samples for assessing PD-L1 expression and overall survival: An updated analysis of KEYNOTE-010 trial. Ann Oncol 30: 281-289, 2019.

13. Bordoni R, Ciardiello F, von Pawel J, Cortinovis D, Karagiannis T, Ballinger M,Sandler A, Yu W,He P,Matheny C, et al: Patient-reported outcomes in OAK: A phase III study of atezolizumab versus docetaxel in advanced non-small-cell lung cancer. Clin Lung Cancer 19: 441-449.e4, 2018.

14. Antonia SJ, Villegas A, Daniel D, Vicente D, Murakami S, Hui R, Kurata T, Chiappori A, Lee KH, de Wit M, et al; PACIFIC Investigators: overall survival with durvalumab after chemoradiotherapy in stage III NSCLC. N Engl J Med 379: 2342-2350, 2018.

15. Lee SY, Jung DK, Choi JE, Jin CC, Hong MJ, Do SK, Kang HG, Lee WK, Seok Y, Lee EB, et al: PD-L1 polymorphism can predict clinical outcomes of non-small cell lung cancer patients treated with first-line paclitaxel-cisplatin chemotherapy. Sci Rep 6: 25952, 2016.

16. Ma Y, Liu X, Zhu J, Li W, Guo L, Han X, Song B, Cheng S and Jie L: Polymorphisms of co-inhibitory molecules (CTLA-4/PD-1/ PD-L1) and the risk of non-small cell lung cancer in a Chinese population. Int J Clin Exp Med 8: 16585-16591, 2015.

17. Lee SY, Jung DK, Choi JE, Jin CC, Hong MJ, Do SK, Kang HG, Lee WK, Seok Y, Lee EB, et al: Functional polymorphisms in PD-L1 gene are associated with the prognosis of patients with early stage non-small cell lung cancer. Gene 599: 28-35, 2017. 
18. Du W, Zhu J, Chen Y, Zeng Y, Shen D, Zhang N, Ning W, Liu Z and Huang JA: Variant SNPs at the microRNA complementary site in the B7 H1 3' untranslated region increase the risk of non small cell lung cancer. Mol Med Rep 16: 2682-2690, 2017.

19. Yeo MK, Choi SY, Seong IO, Suh KS, Kim JM and Kim KH: Association of PD-L1 expression and PD-L1 gene polymorphism with poor prognosis in lung adenocarcinoma and squamous cell carcinoma. Hum Pathol 68: 103-111, 2017.

20. Chen YB, Mu CY, Chen C and Huang JA: Association between single nucleotide polymorphism of PD-L1 gene and non-small cell lung cancer susceptibility in a Chinese population. Asia Pac J Clin Oncol 10: e1-6, 2014.

21. Cheng S, Zheng J, Zhu J, Xie C, Zhang X, Han X, Song B, Ma Y and Liu J: PD-L1 gene polymorphism and high level of plasma soluble PD-L1 protein may be associated with non-small cell lung cancer. Int J Biol Markers 30: e364-e368, 2015.

22. Nomizo T, Ozasa H, Tsuji T, Funazo T, Yasuda Y, Yoshida H, Yagi Y, Sakamori Y, Nagai H, Hirai T, et al: Clinical impact of single nucleotide polymorphism in PD-L1 on response to nivolumab for advanced non-small-cell lung cancer patients. Sci Rep 7: 45124, 2017.

23. Vohra M, Sharma AR, Prabhu B N and Rai PS: SNPs in sites for DNA methylation, transcription factor binding, and miRNA targets leading to allele-specific gene expression and Contributing to complex disease risk: A systematic review. Public Health Genomics 23: 155-170, 2020.

24. Mok TSK, Wu YL, Kudaba I, Kowalski DM, Cho BC, Turna HZ, Castro G Jr, Srimuninnimit V, Laktionov KK, Bondarenko I, et al; KEYNOTE-042 Investigators: Pembrolizumab versus chemotherapy for previously untreated,PD-L1-expressing, locally advanced or metastatic non-small-cell lung cancer (KEYNOTE-042): A randomised, open-label, controlled, phase 3 trial. Lancet 393 1819-1830, 2019.

25. Pacheco JM, Gao D and Camidge DR: Extended follow-up on KEYNOTE-024 suggests significant survival benefit for pembrolizumab in patients with PD-L1 $\geq 50 \%$, but unanswered questions remain. Ann Transl Med 7 (Suppl 3): S127, 2019.
26. Yoshimura K, Inoue Y, Karayama M, Tsuchiya K, Mori K, Suzuki Y, Iwashita Y, Kahyo T, Kawase A, Tanahashi M, et al: Heterogeneity analysis of PD-L1 expression and copy number status in EBUS-TBNA biopsy specimens of non-small cell lung cancer: Comparative assessment of primary and metastatic sites. Lung Cancer 134: 202-209, 2019.

27. Inoue Y, Yoshimura K, Mori K, Kurabe N, Kahyo T, Mori H, Kawase A, Tanahashi M, Ogawa H, Inui N, et al: Clinical significance of PD-L1 and PD-L2 copy number gains in non-small-cell lung cancer. Oncotarget 7: 32113-32128, 2016.

28. Livak KJ and Schmittgen TD: Analysis of relative gene expression data using real-time quantitative PCR and the 2(-Delta Delta C(T)) method. Methods 25: 402-408, 2001.

29. Krawczyk P, Grenda A, Wojas-Krawczyk K, Nicoś M, Kucharczyk T, Jarosz B, Reszka K, Pankowski J, Krukowska K, Bożyk A, et al: PD-L1 gene copy number and promoter polymorphisms regulate PD-L1 expression in tumor cells of non-small cell lung cancer patients. Cancer Genet 237: 10-18, 2019.

30. Ikeda S,Okamoto T,Okano S, Umemoto Y, Tagawa T, Morodomi Y, Kohno M, Shimamatsu S, Kitahara H, Suzuki Y, et al: PD-L1 is upregulated by simultaneous amplification of the PD-L1 and JAK2 genes in non-small cell lung cancer. J Thorac Oncol 11: $62-71,2016$

31. NCBI Resource Coordinators: Database resources of the National Center for Biotechnology Information. Nucleic Acids Res 42: D7-D17, 2014.

32. George J, Saito M, Tsuta K, Iwakawa R, Shiraishi K, Scheel AH, Uchida S, Watanabe SI, Nishikawa R, Noguchi M, et al: Genomic amplification of CD274 (PD-L1) in small-cell lung cancer. Clin Cancer Res 23: 1220-1226, 2017.

This work is licensed under a Creative Commons Attribution-NonCommercial-NoDerivatives 4.0 International (CC BY-NC-ND 4.0) License. 